\title{
Pengaruh Budaya Organisasi Dan Disiplin Kerja Terhadap Kinerja Pada Pt. Prima Jaya
}

\author{
${ }^{1}$ Sugandha, ${ }^{2}$ Hendrian Yonata \\ ${ }^{1}$ Universitas Buddhi Dharma \\ ${ }^{2}$ STAB Dharma Widya
}

\begin{abstract}
Alamat Surat
Email: suganda.suganda@ubd.ac.id; hendrian@stabdharmawidya.ac.id
\end{abstract}

Article History:

Diajukan: 30-03-2021; Direvisi: 14-04-2021; Diterima: 28-04-2021

\begin{abstract}
ABSTRAK
Tujuan dari penelitian ini adalah untuk mengetahui Budaya Organisasi dan Disiplin Kerja secara secara parsial (sendiri-sendiri) maupun simultan (bersama-sama) terhadap Kinerja pada PT Prima Jaya, Penelitian dilakukan dengan menyebar kuensioner, sedang metode penelitian dengan menggunakan Simple Random Sampling. Variabel independen dalam penelitian ini adalah Budaya Organisasi dan Disiplin Kerja sedangkan variabel dependen dalam penelitian ini adalah Kinerja. Metode pengumpulan data digunakan dengan cara menyebarkan kuesioner secara langsung kepada Karyawan PT Prima Jaya. Metode analisis yang digunakan dalm penelitian ini menggunakan analisis koefisien determinasi, analisis regresi berganda uji $\mathrm{F}$ serta uji t, dengan menggunakan SPSS Versi 25.00 yang didasarkan pada data dari 100 karyawan PT Prima Jaya. Uji t menunjukkan bahwa besarnya Variabel harga $\left(\mathrm{X}_{1}\right)$ secara parsial berpengaruh positif dan signifikan ((nilai $\mathrm{t}$ hitung Budaya Organisasi 2.843. $>\mathrm{t}_{\text {tabel }} 1,66071$ dan $.005<0.05$ terhadap Kinerja Pada PT. Prima Jaya dan Variabel Disiplin kerja $\left(\mathrm{X}_{2}\right)$ secara parsial berpengaruh positif dan signifikan (nilai $\mathrm{t}$ hitung Disiplin Kerja $2.843>\mathrm{t}_{\text {tabel }} 1,66071$ dan $.020<0.05$ terhadap Kinerja Pada PT. Prima Jaya Dari hasil uji F diperoleh hasil untuk Nilai $F$ hitung sebesar 30.918 dengan nilai signifikansi sebesar 0.000 sehingga nilai $F$ hitung $>F$ tabel atau 249,643 > 3,09 atau tingkat signifikasi (sig) $0.000<0.05$, maka dapat disimpulkan berpengaruh secara simultan (bersama-sama) antara budaya organisasi dan disiplin kerja terhadap Kinerja Pada PT. Prima Jaya dan nilai adjusted $R^{2}$ dalam penelitian ini artinya variansi dalam Kinerja dapat dijelaskan oleh budaya organisasi dan disiplin kerja melalui model sebesar $56.3 \%$ dan sisanya $43,7 \%$ berasal dari variabel lain diluar variabel budaya organisasi dan disiplin kerja. Atau dengan kata lain besarnya kontribusi/sumbangan budaya organisasi dan disiplin kerja adalah sebesar $56.3,9 \%$, sisanya $43.7 \%$ berasal dari variabel lain diluar variabel budaya organisasi dan disiplin kerja.
\end{abstract}

Kata Kunci: Budaya organisasi; disiplin kerja dan kinerja 


\section{ABSTRACT}

The purpose of this study was to determine the Organizational Culture and Work Discipline partially (individually) or simultaneously (jointly) on the performance of PT Prima Jaya. The research was carried out by spreading questionnaires, while the research method was using Simple Random Sampling. The independent variable in this study is Organizational Culture and Work Discipline while the dependent variable in this study is performance. Data collection methods are used by distributing questionnaires directly to employees of PT Prima Jaya. The analytical method used in this study uses the coefficient of determination analysis, multiple regression analysis of the $F$ test and $t$ test, using SPSS Version 25.00 which is based on data from 100 employees of PT Prima Jaya. The t test shows that the price variable (X1) partially has a positive and significant effect (( $t$ value of Organizational Culture 2.843.> T table 1.66071 and $.005<0.05$ on Performance at PT. Prima Jaya and Work Discipline Variable (X2) respectively. partial positive and significant effect ( $t$ value of Work Discipline 2.843> ttable 1.66071 and 020 $<0.05$ on Performance at PT. Prima Jaya From the results of the F test the results obtained for the calculated $F$ value of 30,918 with a significance value of 0.000 so that the $F$ value $>F$ table or 249.643> 3.09 or the level of significance (sig) $0.000<0.05$, it can be concluded that the effect simultaneously (together) between organizational culture and work discipline on performance at PT. Prima Jaya and the adjusted R2 value in this study This means that the variance in performance can be explained by organizational culture and work discipline through a model of $56.3 \%$ and the remaining $43.7 \%$ comes from other variables outside of cultural variables. organization and work discipline. Or in other words, the contribution / contribution of organizational culture and work discipline is $56.3 .9 \%$, the remaining $43.7 \%$ comes from other variables outside the variables of organizational culture and work discipline.

\section{Keywords: Organizational culture, work discipline and performance}

\section{Pendahuluan}

Dalam sebuah perusahaan, sumber daya manusia tentunya menjadi bagian yang sangat penting dalam kelangsungan perkembangan suatu perusahaan. Sumber daya manusia tersebut merupakan keseluruhan individu yang bekerja diperusahaan tersebut. Pada dasarnya, setiap perusahaan yang dibentuk tentunya memiliki suatu tujuan yang ingin dicapai, baik itu perusahaan industri, perdagangan, maupun jasa. Tidak dapat disanggah, bahwa dalam era perkembangan teknologi dengan persaingan yang begitu ketat akan menimbulkan masalah, dimana masalah tersebut hanya manusia lah yang dapat menyelesaikannya, karena berjalannya suatu perusahaan dikarenakan bukan adanya teknologi yang canggih, pendanaan operasi yang tersedia, ataupun sarana prasarana yang ada, semua tidak akan berarti jika tidak adanya sumber daya manusia yang berperan untuk menggerakan perusahaan guna untuk menyelesaikan permasalahan yang terjadi. Manusia memiliki kedudukan yang sangat penting didalam suatu perusahaan, karena manusia merupakan pelaku perencanaan, penggerak, serta penentu terwujudnya suatu tujuan perusahaan. Maka dari itu, manusia termasuk dalam asset perusahaan yang penting untuk diperhatikan perkembangannya dalam suatu perusahaan, terutama untuk menghadapi era globalisasi.

Kesuksesan suatu perusahaan juga dapat dilihat dari bagaimana kinerja karyawan yang ada dalam perusahaan tersebut. Kinerja merupakan sebuah hasil kerja yang sesuai dengan aturan serta standar yang ditetapkan oleh masing-masing perusahaan, kinerja tersebut yang akan membawa perusahaan untuk mencapai tujuan-tujuan yang telah ditetapkan oleh perusahaan. Dalam hal ini, perusahaan harus memiliki cara tersendiri untuk mendorong para karyawannya 
agar dapat bekerja secara efektif dan efisien guna untuk menyelesaikan tanggung jawabnya sesuai dengan waktu dan ketentuan yang diberikan oleh perusahaan, karena setiap perusahaan tentunya berharap agar tujuan perusahaan dapat terealisasikan, salah satunya dengan cara meningkatkan kinerja karyawan melalui pelatihan dan juga pengembangan sumber daya manusia.

Peningkatan kinerja merupakan kondisi yang sangat penting agar perusahaan dapat mencapai tujuan organisasi sesuai dengan target-target yang sebelumnya telah ditetapkan. Namun dalam hal ini, masih banyak karyawan yang tidak menunjukkan kinerja yang optimal. Ada beberapa karyawan yang hanya menunjukan kinerja yang baik jika diawasi oleh atasan. Jika hal ini terus terjadi, maka tujuan organisasi akan sulit untuk dicapai.

Didalam perusahaan, tentunya hasil kerja atau kinerja setiap karyawan dipengaruhi oleh banyak faktor, seperti faktor motivasi, kompensasi, gaya kepemimpinan, lingkungan kerja, dan lain sebagainya. Dalam hal ini, budaya organisasi juga menjadi salah satu faktor yang dapat mempengaruhi kinerja karyawan. Budaya organisasi perlu diperhatikan oleh perusahaan karena budaya organisasi merupakan karakteristik yang tidak tampak, dimana karakter ini merupakan kebiasaan-kebiasaan karyawan dalam organisasi, dimana hal ini dapat menjadi contoh dan pembanding antara suatu organisasi dengan organisasi-organisasi lainnya. Budaya organisasi juga dapat disebut sebagai perilaku yang tentunya dapat diterima serta dipahami secara bersama yang mencerminkan nilai serta norma perilaku anggota organisasi.

Kinerja karyawan akan meningkat apabila budaya organisasi pada perusahaan berjalan dengan baik, dimana hal ini akan menimbulkan kepuasan kerja tersendiri bagi karyawan. Budaya organisasi perlu diperhatikan oleh perusahaan karena secara tidak langsung, karyawan, terutama karyawan baru akan belajar dan beradaptasi dengan budaya di perusahaan tersebut guna untuk berbaur dan menyesuaikan diri dengan keadaan sekitar perusahaan agar karyawan mudah diterima dilingkungan perusahaan. Budaya organisasi yang kurang baik atau lemah, cenderung akan menjauhkan perusahaan dari visi dan tujuan yang sangat ingin dicapai oleh perusahaan. Sebaliknya, jika budaya organisasi berjalan dengan sebagaimana mestinya atau dengan baik, maka akan mendekatkan perusahaan dengan visi dan tujuan perusahaan. Maka dari itu, perusahaan perlu mengelola budaya organisasi dengan benar agar budaya organisasi menjadi kuat dan positif, sehingga karyawan dalam perusahaan tersebut terdorong dan terpengaruh akan perilaku yang positif dan bekerja secara produktif, efektif, dan efisien.

Namun nyatanya, masih terdapat perusahaan yang tidak acuh dengan banyaknya pelanggaran yang terjadi didalam perusahaan tersebut, seperti tidak memberikan sanksi kepada karyawan yang telah melanggar peraturan yang telah dibuat dan ditetapkan oleh perusahaan lebih dari tiga kali. Perusahaan hanya memberikan teguran atau peringatan secara lisan, dimana hal ini tidak akan membuat karyawan tersebut merasa jerah. Dengan perilaku karyawan yang terus menerus mengulang kesalahan yang sama, mengakibatkan hal ini menjadi budaya dalam organisasi tersebut.

Guna untuk mencapai dan meningkatkan kinerja yang optimal, tentunya kedisplinan sangat dibutuhkan dalam melakukan suatu pekerjaan agar tujuan perusahaan dapat tercapai. Permasalahan yang sering ditemui yaitu kurangnya ketaatan karyawan dalam mematuhi peraturan dan nilai yang telah dibuat oleh perusahaan, salah satunya yaitu terkait dengan disiplin kerja. Disiplin kerja juga termasuk dalam salah satu faktor yang tentunya dapat mempengaruhi kinerja karyawan karena disiplin kerja termasuk dalam salah satu bentuk sikap menghargai, menghormati, serta taat pada aturan-aturan yang telah dibuat oleh perusahaan guna untuk mencapai visi dan tujuan perusahaan. 
Kedisplinan merupakan suatu hal yang harus dijaga, dipertahankan, serta ditingkatkan karena apabila karyawan terbiasa bekerja sesuai dengan aturan yang telah ditetapkan maka tujuan perusahaan akan semakin cepat untuk dicapai. Dengan adanya kedisplinan dalam perusahaan atau organisasi, diharapkan hal ini dapat mendorong semangat kerja yang tinggi karena karyawan merasa mereka diikutsertakan dalam pencapaian tujuan perusahaan dan merasa bahwa hasil kerja mereka diakui serta dihargai oleh perusahaan.

Namun pada kenyataannya, masih ada karyawan yang melanggar peraturan yang telah dibuat dan ditetapkan oleh perusahan seperti salah satu contohnya hadir tidak tepat waktu atau terlambat dan istirahat lebih dahulu sebelum jam yang telah dibuat dan ditetapkan oleh perusahan. Hal ini memperlihatkan bahwa sikap disiplin dalam diri karyawan tersebut masih belum terbentuk sepenuhnya. Hal ini juga memperlihatkan bahwa karyawan tersebut tidak menunjukkan kinerja yang optimal, jelas ini tidak seperti apa yang diharapkan oleh perusahaan.

Berdasarkan faktor-faktor yang diuraikan diatas, peneliti tertarik untuk melakukan penelitian pada PT. Prima Jaya untuk mengetahui Kinerja Karyawan pada perusahaan tersebut dengan penelitian yang berjudul "PENGARUH BUDAYA ORGANISASI DAN DISIPLIN KERJA TERHADAP KINERJA KARYAWAN PADA PT. PRIMA JAYA".

\subsection{Rumusan Masalah}

Sesuai dengan identifikasi masalah yang telah dijabarkan diatas, maka rumusan masalah dalam penelitian ini sebagai berikut:

1. Seberapa besar pengaruh budaya organisasi terhadap kinerja karyawan pada PT. Prima Jaya?

2. Seberapa besar pengaruh disiplin kerja terhadap kinerja karyawan pada PT. Prima Jaya?

3. Seberapa besar pengaruh disiplin kerja dan budaya organisasi terhadap kinerja karyawan pada PT. Prima Jaya?

\section{Kajian Teori}

\subsection{Budaya Organisasi}

Menurut (Robbins dan Judge 2015, 226) menyatakan bahwa: "Budaya organisasi didefenisikan sebagai sebuah sistem makna bersama yang dianut oleh para anggota organisasi yang membedakan organisasi suatu perusahaan dengan organisasi yang lainnya." Menurut (Irhan Fahmi 2016, 186) menyatakan bahwa: "Budaya organisasi merupakan suatu kebiasaan yang telah berlangsung lama dan dipakai serta diterapkan dalam kehidupan aktivitas kerja sebagaisalah satu pendorong untuk meningkatkan kualitas kerja para karyawan dan manajer perusahaan." Zwell (2000) dalam (Sedarmayanti 2017, 347) menyatakan bahwa: "Budaya organisasi merupakan pandangan hidup organisasi dihasilkan melalui pergantian generasi pegawai. Budaya mencakup siapa kami, apa yang kita percaya, dan apa yang kita lakukan." Dan menurut (Sedarmayanti 2017,348) menyatakan bahwa: "Budaya organisasi merupakan nilai, anggapan, asumsi, sikap, dan norma perilaku yang telah melembaga, kemudian mewujudkan dalam penampilan, sikap, dan tindakan sehingga menjadi identitas dan organisasi tertentu."

\subsection{Displin Kerja}

Menurut (Arif Yusuf Hamali 2018,214) defisini disiplin kerja yaitu: "Disiplin adalah suatu kekuatan yang berkembang didalam tubuh karyawan dan menyebabkan karyawan dapat menyesuaikan diri dengan sukarela pada keputusan peraturan dan nilai-nilai tinggi dari pekerjaan dan perilaku." Menurut (Lijan Poltak Sinambela 2016.335) menyatakan bahwa: 
"Disiplin kerja adalah kesadaran dan kesediaan pegawai menaati semua peraturan organisasi dan norma-norma sosial yang berlaku dan Disiplin kerja adalah kemampuan kerja seseorang untuk secara teratur, tekun secara terus-menerus, dan bekerja sesuai dengan aturan-aturan yang sudah ditetapkan.” Menurut (Malayu S.P Hasibuan 2017,193) menyatakan bahwa: "Kedisiplinan merupakan fungsi operatif MSDM yang terpenting karena semakin baik disiplin karyawan, semakin tinggi prestasi kerja yang dapat dicapai. Tanpa disiplin karyawan yang baik, sulit bagi organisasi perusahaan mencapai hasil yang optimal". Menurut Wursanto yang dikutip oleh Darsono Prawironegoro dan Dewi Utari (2016,117), menyatakan bahwa: "Disiplin adalah suatu keadaan yang menyebabkan atau memberikan dorongan kepada karyawan untuk berbuat dan melakukan segala kegiatan sesuai dengan norma-norma dan aturan-aturan yang telah ditetapkan. Menurut (Irham Fahmi 2016,65) menyatakan bahwa: "Kedisiplinan adalah tingkat kepatuhan dan ketaatan kepada aturan yang berlaku serta bersedia menerima sanksi atau hukuman jika melanggar aturan yang ditetapkan dalam kedisplinan tersebut. Bentuk sanksi dari tindakan indisipliner bisa berupa teguran lisan maupun teguran tertulis."

\subsection{Kinerja Karyawan}

Menurut (Suparyadi 2015, 300) menyatakan bahwa: "Kinerja karyawan merupakan masalah sentral dalam kehidupan sebuah organisasi karena sebuah organisasi atau perusahaan akan mampu mencapai tujuan atau tidak, sangat tergantung pada sebaik apa kinerja yang ditunjukkan oleh para karyawan." Menurut (Sentot Imam Wahjono 2015, 94) menyatakan bahwa: "Manajemen kinerja adalah proses yang berkesinambungan untuk mengidentifikasi, mengukur, dan mengembangkan kinerja individual dan tim serta menyelaraskan kinerja mereka dengan tujuan organisasi." Menurut (Irham Fahmi 2016, 137) menyatakan bahwa: "Kinerja merupakan hasil yang diperoleh oleh suatu organisasi baik organisasi tersebut bersifat profit oriented dan non profit oriented yang dihasilkan selama satu periode waktu." Menurut Prawirosentono (1999) dalam (Lijan Poltak Sinambela 2016,481) menyatakan bahwa: "Kinerja adalah hasil kerja yang dicapai oleh seseorng atau sekelompok orang dalam suatu organisasi, sesuai dengan wewenang dan tanggung jawab masing-masing, dalam rangka upaya mencapai tujuan organisasi bersangkutan secara legal, tidak melanggar hukum dan sesuai dengan moral dan etika." Menurut (Anwar Prabu Mangkumanegara 2017,67) mendefinisikan bahwa: "Kinerja adalah hasil kerja secara kualitas dan kuantitas yang dicapai oleh seorang pegawai dalam melaksanakan tugasnya sesuai dengan tanggung jawab yang diberikan."

\subsection{Hipotesis}

1. Diduga bahwa Budaya Organisasi $\left(\mathrm{X}_{1}\right)$ berpengaruh signifikan terhadap Kinerja Karyawan (Y).

2. Diduga bahwa Disiplin Kerja $\left(\mathrm{X}_{2}\right)$ berpengaruh signifikan terhadap Kinerja Karyawan (Y).

3. Diduga bahwa Budaya Organisasi $\left(\mathrm{X}_{1}\right)$ dan Disiplin Kerja $\left(\mathrm{X}_{2}\right)$ berpengaruh signifikan terhadap Kinerja Karyawan (Y).

\section{HASIL DAN PEMBAHASAN}

Pada penelitian ini penulis mengambil pengaruh budaya organisasi dan disiplin kerja terhadap kinerja karyawan pada PT. Prima Jaya.

Dan responden untuk dijadikan sampel dalam menjawab pernyataan-pernyataan yang diajukan penulis mengenai pengaruh budaya organisasi dan disiplin kerja terhadap kinerja 
pada PT. Prima Jaya dalam bentuk beberapa pernyataan atau kuensioner yang diajukan kepada 100 Karyawan PT Prima Jaya.

\subsection{PENGUJIAN ASUMSI REGRESI}

a. Uji Normalitas

Penelitian ini menggunakan plot probabilitas normal (Normal probability plot) untuk menguji kenormalitasan jika penyebaran data (titik) disekitar sumbu diagonal dan mengikuti arah garis diagonal, maka model regresi memenuhi asumsi normalitas.

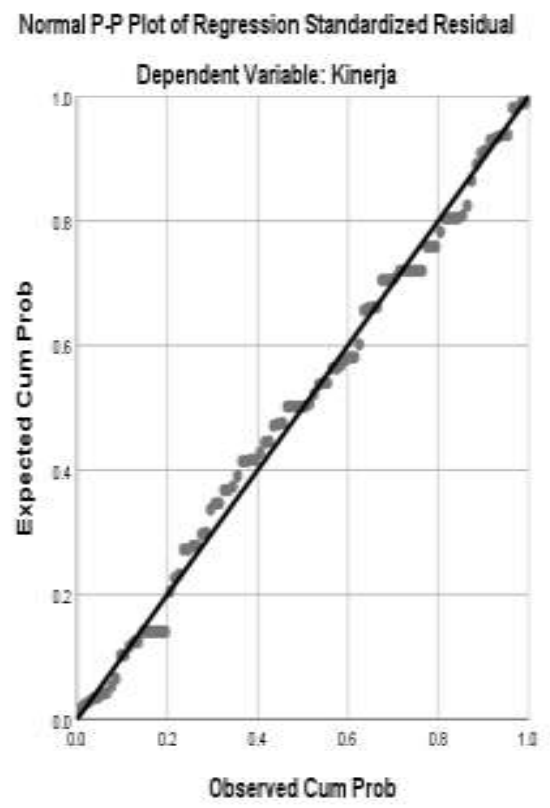

Sumber: Data diolah

\section{Gambar 1. Hasil Uji Normalitas Menggunakan Grafik P.Plot}

Gambar 1 menunjukkan data menyebar di sekitar garis diagonal dan mengikuti arah garis diagonal atau grafik histogram sehingga dapat disimpulkan data tersebut menunjukkan pola distribusi normal. Oleh Karen itu memenuhi asumsi normalitas.

b. Uji Heteroskedastisitas

Uji Heterokesdatisitas digunakan untuk menguji apakah dalam sebuah regresi terdapat kesamaan varians dari residu dari satu pengamatan ke pengamatan yang lain sama. Cara mendeteksi heterokesdatisitas dalam penelitian ini dengan melihat pola sebaran grafik scatter plot. Jika ada pola tertentu, seperti titik yang ada berbentuk suatu pola tertentu yang teratur (bergelombang, melebar, kemudian menyempit) maka telah terjadi heteroskedestisitas. Dilakukan untuk menguji apakah dalam sebuah model regresi, terjadi ketidaksamaan varians dari residual dari satu pengamatan ke pengamatan yang lain. Deteksi ada tidaknya heteroskedastisitas dilakukan dengan melihat ada tidaknya pola tertentu pada grafik scatterplot antara SRESID dan ZPRED. Hasil uji heteroskedastisitas terlihat pada gambar 3. 


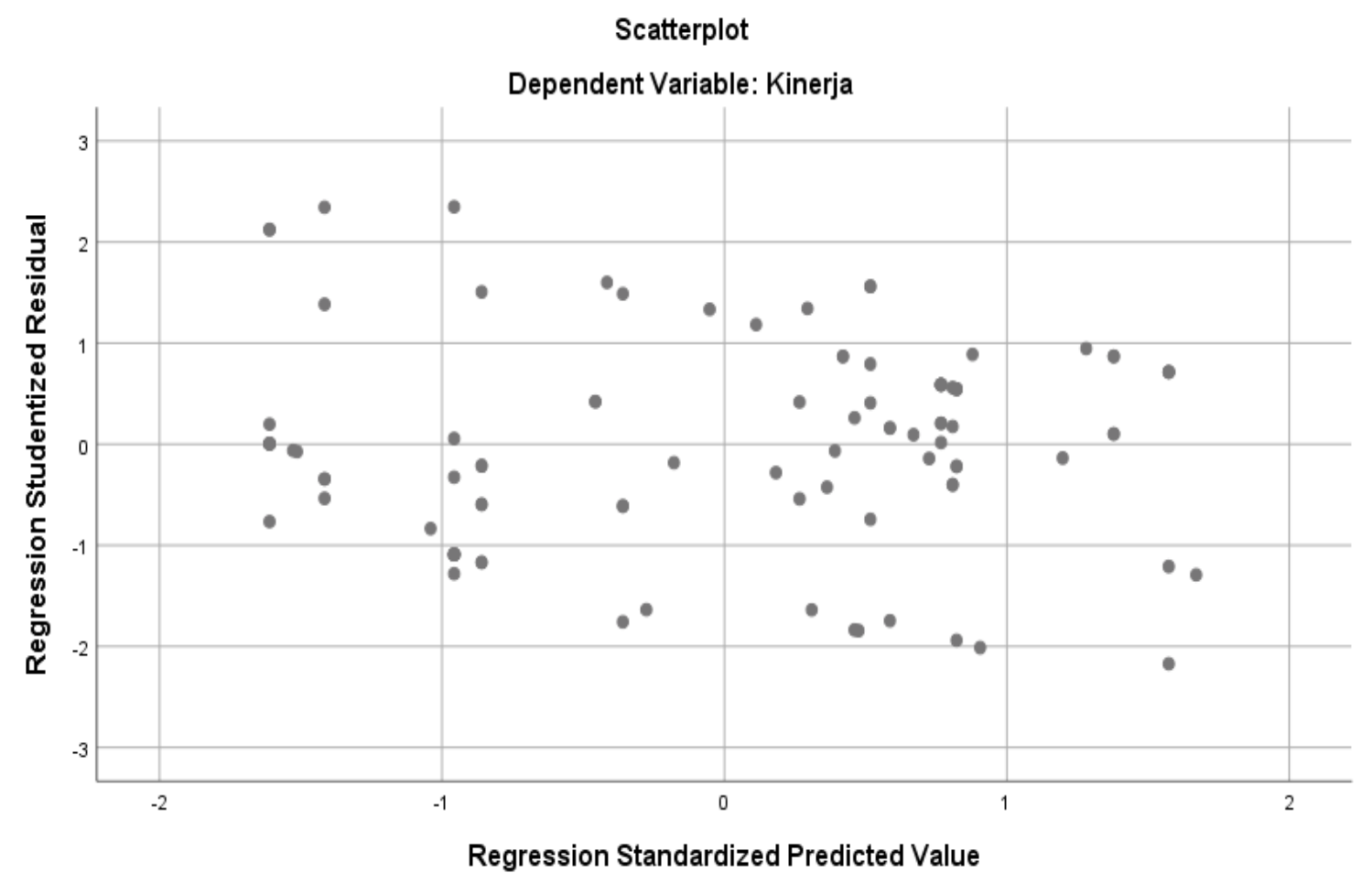

Gambar 3. Grafik Scatterplot

Gambar 3 menunjukkan bahwa titiktitik yang dihasilkan menyebar secara acak dan tidak membentuk pola atau trend garis tertentu. Hal ini berarti data tersebar di atas dan di bawah angka 0 sehingga model ini bebas dari masalah heteroskedastis.

c. Uji Multikolinearitas

Uji multikolinearitas bertujuan untuk menguji apakah model regresi ditemukan adanya korelasi antar variabel bebas (independent). Dalam model regresi yang baik seharusnya tidak terjadi korelasi diantara variabel bebas. Uji Multikolineritas dilakukan dengan melihat Tolerance dan Variance Inflasion Factor (VIF). Apabila nilai tolerance $<0.10$ atau sama dengan nilai VIF $>10$. (Ghozali, 2010:91). Hasil pengujian multikorelasi terlihat di tabel 4

Tabel 4. Hasil Uji Multikolinieritas

\begin{tabular}{|l|r|r|c|}
\hline \multicolumn{1}{|c|}{ Variabel } & Tolerance & \multicolumn{1}{c|}{ VIF } & Keterangan \\
\hline Budaya Organisasi $\left(\mathrm{X}_{1}\right)$ & 0,423 & 2,365 & Tidak terjadi Multikolinearitas \\
\hline Disiplin Kerja $\left(\mathrm{X}_{2}\right)$ & 0,392 & 2,552 & Tidak terjadi Multikolinearitas \\
\hline
\end{tabular}

Sumber: Data diolah

Dari tabel $4 \mathrm{di}$ atas menunjukkan hasil perhitungan nilai VIF (Variance Inflation Factor) masing-masing variabel independen dalam model berada di bawah 10 dan nilai tolerance-nya berada di atas 0,10 sehingga model regresi bebas dari masalah multikolineritas. 


\subsection{Analisis Linier Berganda}

Untuk mengetahui ada tidaknya hubungan antara variabel $\mathrm{X}_{1}$ (Harga), variabel $\mathrm{X}_{2}$ (Lokasi), variabel $\mathrm{X}_{3}$ (Promosi) dan variabel $\mathrm{X}_{4}$ (Pelayanan) terhadap $\mathrm{Y}$ (pengambilan keputusan menginap), serta mengukur kuat tidaknya hubungan tersebut, maka digunakan analisa regresi berganda dengan perhitungan SPSS (Statistical Package Service Softition), Versi 25.0.

Hasil Perhitungan Regresi Berganda

\begin{tabular}{|l|r|r|r|}
\hline \multicolumn{1}{|c|}{ Variabel } & Koefisien Regresi & \multicolumn{1}{c|}{ T hitung } & \multicolumn{1}{c|}{ Sig } \\
\hline Konstanta & 9.269 & 3.335 & .001 \\
\hline Budaya Organisasi $\left(\mathrm{X}_{1}\right)$ & .407 & 2.843 & .005 \\
\hline Disiplin Kerja $\left(\mathrm{X}_{2}\right)$ & .348 & 2.373 & .020 \\
\hline F hitung $: 30.918$ & & & \\
Sig $: 0.000$ & & & \\
\hline Adjusted R $: 0.557$ & & & \\
\hline R $: 0.624^{\mathrm{a}}$ & & & \\
\hline
\end{tabular}

Sumber : Data diolah

Berdasarkan tabel diatas dapat dibentuk persamaan regresi berganda:

$\mathrm{Y}=9.269+0407 \mathrm{X}_{1}+0,348 \mathrm{X}_{2}+\ldots . \beta$

Persamaan tersebut mempunyai arti sebagai berikut:

1. Konstanta sebesar 9.269 menunjukkan bahwa apabila Budaya Organisasi $\left(X_{1}\right)$, dan Disiplin Kerja $\left(\mathrm{X}_{2}\right)$ dianggap tetap, tetapi dipengaruhi oleh variabel di luar model, maka diperkirakan Kinerja (Y) akan mengalami kenaikan sebesar 9.269

2. Koefisien regresi Budaya Organissi $\left(\mathrm{X}_{1}\right)$ sebesar 0.407 artinya Budaya Organisasi meningkat satu satuan maka Kinerja akan mengalami kenaikan sebesar 0.407 dengan asumsi variabel lain bernilai tetap

3. Koefisien regresi Disiplin Kerja $\left(\mathrm{X}_{2}\right)$ sebesar 0.348 artinya lokasi meningkat satu satuan maka Kinerja akan mengalami kenaikkan sebesar 0.348 dengan asumsi variabel lain bernilai tetap

\section{A. Uji t}

\begin{tabular}{|c|c|c|c|c|c|c|c|c|}
\hline \multicolumn{9}{|c|}{ Coefficients $^{\mathbf{a}}$} \\
\hline \multirow[b]{3}{*}{ Model } & & \multirow{2}{*}{\multicolumn{2}{|c|}{$\begin{array}{c}\text { Unstandardized } \\
\text { Coefficients }\end{array}$}} & \multirow{3}{*}{$\begin{array}{c}\text { Standardized } \\
\text { Coefficients } \\
\text { Beta } \\
\end{array}$} & \multirow{3}{*}{$\mathrm{T}$} & \multirow{3}{*}{ Sig. } & \multirow{2}{*}{\multicolumn{2}{|c|}{ Collinearity Statistics }} \\
\hline & & & & & & & & \\
\hline & & $\mathrm{B}$ & Std. Error & & & & Tolerance & VIF \\
\hline \multirow[t]{3}{*}{1} & (Constant) & 9.269 & 2.779 & & 3.335 & .001 & & \\
\hline & Budaya Organisasi & .407 & .143 & .360 & 2.843 & .005 & .392 & 2.552 \\
\hline & Disiplin Kerja & .348 & .147 & .301 & 2.373 & .020 & .392 & 2.552 \\
\hline
\end{tabular}

a. Dependent Variable: Kinerja

a. Variabel Budaya Organissi $\left(\mathbf{X}_{1}\right)$ secara parsial berpengaruh positif dan signifikan (nilai $t$ hitung Budaya Organisasi 2.843. $>t_{\text {tabel }} 1,66071$ dan $.005<0.05$ terhadap Kinerja Pada PT. Prima Jaya 
b. Variabel Disiplin Kerja $\left(\mathbf{X}_{2}\right)$ secara parsial berpengaruh positif dan signifikan (nilai t hitung Disiplin Kerja $2.843>t_{\text {tabel }} 1,66071$ dan $.020<0.05$ terhadap Kinerja Pada PT. Prima Jaya

\section{B. Uji F}

\begin{tabular}{|c|c|c|c|c|c|c|}
\hline \multicolumn{7}{|c|}{ ANOVA $^{a}$} \\
\hline Model & & Sum of Squares & $\mathrm{df}$ & Mean Square & $\mathrm{F}$ & Sig. \\
\hline \multirow[t]{3}{*}{1} & Regression & 1731.098 & 2 & 865.549 & 30.918 & $.000^{\mathrm{b}}$ \\
\hline & Residual & 2715.492 & 97 & 27.995 & & \\
\hline & Total & 4446.590 & 99 & & & \\
\hline
\end{tabular}

a. Dependent Variable: Kinerja

b. Predictors: (Constant), Disiplin Kerja, Budaya Organisasi

Dari hasil uji $\mathrm{F}$ diperoleh hasil untuk Nilai $\mathrm{F}$ hitung sebesar 30.918 dengan nilai signifikansi sebesar 0.000 sehingga nilai $\mathrm{F}_{\text {hitung }}>\mathrm{F}_{\text {tabel }}$ atau 249,643 $>$ 3,09 atau tingkat signifikasi (sig) $0.000<0.05$, maka dapat disimpulkan berpengaruh secara simultan (bersama-sama) antara budaya organisasi dan disiplin kerja terhadap Kinerja Pada PT. Prima Jaya.

\section{Uji Koefisien Determinasi $\left(\mathbf{R}^{2}\right)$}

\begin{tabular}{|c|c|c|c|c|}
\hline \multirow[b]{2}{*}{ Model } & \multicolumn{3}{|c|}{ Model Summary $^{b}$} & \multirow[b]{2}{*}{$\begin{array}{c}\text { Std. Error of the } \\
\text { Estimate }\end{array}$} \\
\hline & $\mathrm{R}$ & R Square & $\begin{array}{l}\text { Adjusted R } \\
\text { Square } \\
\end{array}$ & \\
\hline 1 & $.750^{\mathrm{a}}$ & .563 & .557 & 3.755 \\
\hline
\end{tabular}

a. Predictors: (Constant), Disiplin Kerja, Budaya Organisasi

b. Dependent Variable: Kinerja

Berdasarkan hasil perhitungan dengan SPSS for window nilai adjusted $R^{2}$ dalam penelitian ini artinya variansi dalam Kinerja dapat dijelaskan oleh budaya organisasi dan disiplin kerja melalui model sebesar $56.3 \%$ dan sisanya $43,7 \%$ berasal dari variabel lain diluar variabel budaya organisasi dan disiplin kerja. Atau dengan kata lain besarnya kontribusi/sumbangan budaya organisasi dan disiplin kerja adalah sebesar 56.3,9\%, sisanya $43.7 \%$ berasal dari variabel lain diluar variabel budaya organisasi dan disiplin kerja 


\section{Daftar Pustaka}

Amirullah. Pengantar Manajemen (Fungsi, Proses, Pengendalian). Jakarta: Mitra Wacana Media, 2015.

Fahmi, Irham. Pengantar Manajemen Sumber Daya Manusia (Konsep dan Kinerja). Jakarta: Penerbit Mitra Wacana Media, 2016.

Hamali, Arif Yusuf. Pemahaman Manajemen Sumber Daya manusia (Strategi Mengelola Karyawan). Yogyakarta: CAPS (Center for Academic Publishing Service), 2018.

Hasibuan, Malayu S.P. Manajemen Sumber Daya Manusia. Edisi Revisi. Jakarta: PT. Bumi Aksara, 2017.

Haudi., Hadion Wijoyo. (2021). Pengantar Ilmu Pemerintahan. Insan Cendekia Mandiri.

Mangkunegara, Anwar Prabu. Manajemen Sumber Daya Manusia Perusahaan. Bandung: PT. REMAJA ROSDAKARYA, 2017.

Prawironegoro, Darsono dan Dewi Utari. Manajemen SDM Abad 21 (Sumber Daya Manusia). Edisi Revisi. Jakarta: Mitra Wacana Media, 2018.

Priansa, Donni Juni. Manajemen Kinerja Kepegawaian (dalam Pengelolaan SDM Perusahaan). Bandung: CV. PUSTAKA SETIA, 2017.

Riduwan. Metode Teknik Menyusun Tesis. Bandung: Alfabeta, 2015.

Sedarmayanti. Perencanaan dan Pengembangan Sumber Daya Manusia (Untuk Meningkatkan Kompetensi, Kinerja, dan Produktivitas Kerja). Bandung: PT. Refika Aditama, 2017.

Sinambela, Lijan Poltak. Manajemen Sumber Daya Manusia (Membangun Tim Kerja yang Solid Untuk Meningkatkan Kinerja). Jakarta: PT. Bumi Aksara, 2016.

Suci, I. G. S., Suyanta, I. W., Darna, I. W., Wijoyo, H., \& Setyawati, E. (2020). A Measure Of Effectiveness Level Of Online Learning Amid Covid-19 Pandemic In The Course Of The Project Management Information Systems (Case Study In STIKOM Yos Sudarso Purwokerto). Journal of Critical Reviews, 7(12), 4059-4069.

Sudaryono. Aplikasi Statistik untuk Penelitian. Jakarta Pusat: Lentera Ilmu Cendekia, 2014.

Sudaryono. Metodologi Penelitian (Cetakan ke-1). Jakarta: Rajawali Pers, 2017.

Sugandha, S. (2019). Pengaruh Lingkungan Kerja Dan Stress Kerja Terhadap Kinerja Karyawan (Studi Kasus di PT. KEONG NUSANTARA ABADI). Primanomics: Jurnal Ekonomi \& Bisnis, 17(2), 38-47.

Sugandha, S., Wibowo, F. P., \& Hendra, H. (2019). PENGARUH PELATIHAN DAN PENGEMBANGAN SUMBER DAYA MANUSIA TERHADAP PRESTASI KERJA KARYAWAN PT. JEMBO ENERGINDO. Dynamic Management Journal, 3(2).

Sugiyono. Cara Mudah Menyusun Skripsi, Tesis, dan Disertasi. Bandung: Alfabeta, 2016. 
Sugiyono. Metode Penelitian (Kuantitatif, Kualitatif, dan R\&D). Bandung: Anggota Ikatan Penerbit Indonesia (IKAPI), 2017.

Sugiyono. Metode Penelitian Bisnis. Bandung: Alfabeta, 2017.

Sujarweni, V. Wiratna. SPSS untuk Penelitian, Yogyakarta: Pustaka Baru Press, 2015.

Sunyoto, Danang. Manajemen Dan Pengembangan Sumber Daya Manusia. Jakarta: CAPS (Center for Academic Publishing Service), 2015.

Suparyadi. Manajemen Sumber Daya Manusia. Yogyakarta: CV. ANDI OFFSET, 2015.

Sutrisno, Edy. Manajemen Sumber Daya Manusia. Jakarta: Kencana Prenada Media Group, 2016.

Wahjono, Sentot Imam. Manajemen Sumber Daya Manusia. Jakarta: Penerbit Salemba Empat, 2015.

Wibowo, F. P., Sugandha, S., \& Tholok, F. W. (2020). PENGARUH BUDAYA ORGANISASI DAN LINGKUNGAN KERJA TERHADAP KINERJA (Studi Kasus di PT Mutiara Nusantara Globalindo). JURNAL EKONOMI DAN KEWIRAUSAHAAN, 20(3).

Widiyanto, G., \& Sugandha, S. (2019). Analisis Pengaruh Marketing Mix Terhadap Keputusan Pembelian Produk Makanan Cepat Saji. Primanomics: Jurnal Ekonomi \& Bisnis, 17(1), 33-44.

Wijoyo, H. (2020). RANCANG BANGUN SISTEM INFORMASI PENGGAJIAN DAN ABSENSI KARYAWAN MEGARA HOTEL PEKANBARU BERBASIS WEB. Ekonam: Jurnal Ekonomi, Akuntansi \& Manajemen, 2(2), 56-76.

Wijoyo, H. Perancangan Sistem Informasi Administrasi pada Quality Fresh Laundry Pekanbaru. JS (Jurnal Sekolah), 4(1), 27-32.

Wijoyo, H. SISTEM INFORMASI PEMESANAN MAKANAN DAN MINUMAN DI RUMAH MAKAN PUTRI MINANG JAYA. JS (JURNAL SEKOLAH), 3(3), 214-224.

Wirawan. Evaluasi Kinerja Sumber Daya Manusia. Jakarta: Salemba Empat, 2015. 